\title{
IMPACT OF PALATAL COVERAGE FOR MAXILLARY IMPLANT ASSISTED OVERDENTURE ON RESPIRATORY PERFORMANCE. SPIROMETRIC EVALUATION
}

\author{
Abdallah M. Ibrahim*, Mohamed Elgamal ${ }^{* *}$ and Mohamed Elgamal ${ }^{*}$
}

\begin{abstract}
Objectives: The purpose was to determine the influence of maxillary implant overdentures with and without palatal coverage on spirometric parameters.

Materials and methods: 14 healthy edentulous patients were participated in this study. All patients were received 4 implants in maxillary arch in canines premolars areas and 2 implants in mandibular canines areas. All patients were received 2 maxillary implant overdentures "with and without palatal coverage" and one mandibular implant overdenture. Locator attachments were used to anchor the overdentures. Spirometry test was performed in three different oral conditions: without prosthesis, with maxillary implant overdenture with palatal coverage, and with palateless implant overdenture. The test was done after 2 months of each overdenture delivery. Spirmetric parameters as, Vital capacity (VC), Peak expiratory flow (PEF), Forced expiratory volume in $1 \mathrm{sec}$. (FEV1), FEV1/FVC (Forced vital capacity), and Maximum expiratory flow between $25 \%$ and $75 \%$ (MEF25-75) were evaluated.
\end{abstract}

Results: There was statistically significant reduction in VC, FEV1/FVC, and MEF25-75 for without prosthesis compared to maxillary implant overdenture with or without palatal coverage ( $\mathrm{p}<0.05)$. Also, there was statistically significant increase in VC, FEV1/FVC, and MEF25-75 for palateless implant overdenture compared to maxillary implant overdenture with palatal coverage $(\mathrm{p}<0.05)$. While there were no significant differences between the different oral conditions in FEV1, and PEF ( $\mathrm{p}>0.05)$.

Conclusion: Covering the palate by dental prosthesis had an adverse effect on respiratory function as using the palateless implant overdenture showed improvement in respiratory performance in comparison to maxillary implant overdenture with palatal coverage.

\footnotetext{
* Lecturer of Prosthodontics Department, Faculty of Dentistry, Mansoura University, Egypt.

** Lecturer of Pulmonary Medicine and Critical Care, Chest Department, Faculty of Medicine, Mansoura University, Egypt.
} 


\section{INTRODUCTION}

Rehabilitation of completely edentulous patients with complete dentures not only allow reestablishing the missing occlusal support but also allow recovery of oral anatomical structures and correctly maintain the morphological anatomy of oral and pharyngeal areas ${ }^{(1)}$. The complete dentures must extend to posterior palatal seal area in the maxilla and to the retro-molar pad in the mandible to gain sufficient retention and stability ${ }^{(2-5)}$. This may lead to decrease in the oral cavity volume and disturbance in important functions like chewing efficiency and speech production ${ }^{(6-8)}$.

Placement of dental implants to retain or support overdentures become a reliable treatment option for both maxillary and mandibular arches ${ }^{(9-12)}$. To obtain a good result with a conventional maxillary implant assisted overdenture, it is better to be extended to cover the palatal area together with good adaptation and good peripheral seal at the borders ${ }^{(13)}$. It was found that retention of the denture was affected by covering the maxillary tuberosity more than covering the palatal area ${ }^{(14)}$. Reduction of the palatal part of maxillary implant assisted overdenture might not affect the retention or stability of the overdenture but provide several benefits for the patient as, decrease gaging reflex, improve taste sensation, better phonetic, and positive effect on rate of salivary flow ${ }^{(15)}$.

Concerning the influence of covering the palate of completely edentulous patients treated with conventional maxillary implant overdentures, a study was conducted on 10 patients with a favorable residual ridge height. It found that 8 patients had more natural feeling with decreased palatal coverage overdentures than with full palatal coverage overdentures. Also it found that the overdentures with reduced palatal coverage were effective as the overdentures with full covering the palatal area ${ }^{(16)}$.

Patient satisfaction was evaluated by another study where 40 participants received three implants to support maxillary implant overdenture. After one year of use with complete palatal coverage overdenture, the palatal coverage was decreased and patient satisfaction was examined by using means of Oral Health Impacts Profile questionnaires after using the overdenture for another one year. It found that $(85 \%)$ of patients preferred overdentures with partial palatal coverage and did not notice any decreased in retention ${ }^{(17)}$.

Respiration is considered as one of the most important vital functions. It is defined as the gases exchange between atmosphere and the living organism to supply the body with its metabolic needs ${ }^{(18)}$. During oral respiration, the existing denture and the other oral tissues are the first structures that contact the air that passing across the upper airways. It has been reported that the size and tone of the pharyngeal musculature were decreased by total edentulism ${ }^{(19,20)}$.

Several studies ${ }^{(21-23)}$ found that there is a strict relationship between the upper airway and orofacial conditions. Wearing complete dentures during spirometric test had some significant effects on the respiratory performances for completely edentulous patients (24-26). Little information was presented about the effect of palatal coverage for implant assisted overdenture on respiratory function. The purpose of this work was to study the effects of maxillary implant assisted overdenture with and without palatal coverage on respiratory function.

\section{MATERIALS AND METHODS}

This prospective cross-over study was carried out on fourteen healthy edentulous patients, their ages were ranged from 45 to 65 years. They were selected from outpatient's clinic of Prosthodontics Department, Faculty of Dentistry, Mansoura University. All patient were nonsmokers, free from any systemic diseases that interfere with implant placement, and free of any respiratory diseases such as bronchial asthma or chronic obstructive pulmonary disease (COPD). Prosthetically, at least one year edentulous period and sufficient restorative 
space ${ }^{(27)}$ to allow for types of prosthesis that were tested. All patients had normal maxillomandibular relationship. Ethical agreement was taken from ethical committee and written consent had gotten from all the participants after illustrating in detail the whole research protocol.

\section{Surgical and prosthetic procedures}

\section{Construction of conventional denture:}

Preliminarily upper and lower irreversible hydrocolloid impressions were made. Special impression trays were constructed. Low fusing green stick compound was used for border molding and final impressions were made using Zinc Oxide Eugenol impression material (Cavex outline, Cavex Holland BV). Maxillary and mandibular record blocks were fabricated on the poured final models using baseplate wax on a trial denture base. Maxillomandibular relationship were registered using Aluwax (Aluwax Dental Products Company, Allendale, MI). Face-bow record used to mount the maxillary master cast on semi adjustable articulator (Hanau H2. Teledyne Hanau. Buffalo. Ny. U.S.A) then mandibular cast was mounted using inter-occlusal record. Protrusive record was taken to adjust the horizontal condylar guidance and the lateral condylar guidance was adjusted according to Hanau equation. After artificial teeth selection, the teeth were set in balanced lingualized occlusion. Wax try-in was done then the dentures were processed in heat cured acrylic resin. Denture insertion was completed and the occlusion was evaluated using articulating paper. Patients were followed up one week after insertion to assess any complaints and assure accurate occlusion. The maxillary and mandibular complete dentures were duplicated into clear acrylic resin duplicates.

\section{Surgical procedures}

The dentures duplicates were modified as a radiographic stents by preparing multiple holes ( $2 \mathrm{~mm}$ depth and $2 \mathrm{~mm}$ width) filled with radiopaque gutta-percha in order to act as reference points during the construction of stereolithographic surgical guide and determine the amount of bone for implant placement ${ }^{(28)}$.

Stereolithographic mucosal supported surgical guide construction following dual scan technique using cone beam computerized tomography (CBCT, i- CAT Vision ${ }^{\circledR}$, Imaging Sciences International, Hatfield, PA). Four parallel implants (TioLogic, Dentaurum) were inserted in the maxillary arch in the canines and premolars areas and two implants placed in the mandibular arch in canine regions by means of guided surgery using submerged surgical technique and delayed loading protocol.

Participants were taken prophylactic antibiotic (875 mg Amoxicillin and Clavulanic acid $125 \mathrm{mg}$ ) one day before implant placement and continued after surgery for one week. Participants were asked to rinse their mouth with chlorohexidine mouthwash just before surgery and continue rinsing their mouth one week after surgery. During the period of osseointegration, all participants used their dentures after relining it with tissue conditioning material (alpha-dent DENTAL TECHNOLOGIES. USA).

\section{Construction of maxillary and mandibular implant assisted overdenture:}

After Osseo integration period, the locator attachments (tioLogic LOCATOR) were secured to implants (Fig. 1) and all patients were received:

1- Single design of mandibular implant retained overdenture where the mandibular complete denture was changed into implant retained overdenture by incorporating the housings of the locator attachments to the intaglio surface of the lower denture by direct pick up technique.

2- Two design of maxillary implant assisted overdentures:

A- Maxillary implant assisted overdenture with palatal coverage: The maxillary complete 
denture was changed into implant overdenture by incorporating the housings of the locator attachments to the intaglio surface of the upper denture by direct pick up technique (Fig.2).

\section{B-Palateless maxillary implant assisted} overdenture: The maxillary denture acrylic resin duplicate was relieved to be used as special tray. After placement the locator abutments and housings were finished, the relieved denture duplicate was used to make the final impression using medium body rubber base impression material (Zhermack, Italy). A face-bow record was used for mounting the maxillary model. Inter maxillary relationship was obtained by using the denture duplicate. Before separating the model from the denture impression of the duplicate, a putty index was constructed on the teeth position to allow for setting the teeth in a the same arrangement to the first denture. The final model was sent to the laboratory for construction of the palateless overdenture metal framework. After try in of the teeth set on the metal framework, the final overdentures were processed, finished and polished. After overdenture insertion, the locator attachments housings were incorporated to the overdenture by using direct pick up technique. (Fig. 3)

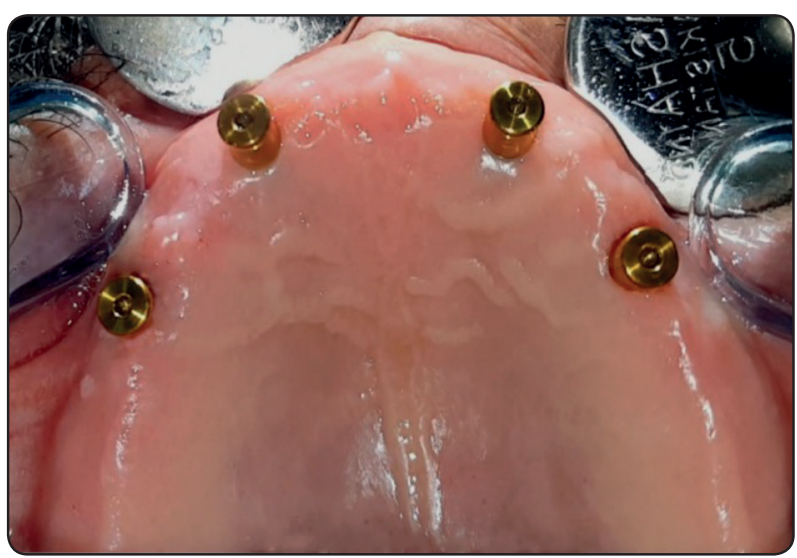

Fig. (1) Locator abutments inserted intra orally

\section{Spirometric test procedure:}

The participants were instructed not to do any heavy physical activity like walking, or climbing stairs one hour before performing the test, and instructed to wear quite large clothes to permit unbounded respiratory movements of the abdomen and chest. The procedures of the test were illustrated to all participants and the proper technique was demonstrated. Spirometric test was done by an experienced technician according to the standards of the American Thoracic Society ${ }^{(29,30)}$.(Fig. 4)

The spirometry test was carried out at three different oral conditions for the participants. The first test was performed without prosthesis (WOP), and its measurements were considered as the control values. The second test was done after 2 month of insertion of maxillary implant assisted overdenture with palatal coverage (MIOD) opposed by lower implant retained overdenture, and the third test carried out after 2 months of insertion of palateless maxillary implant assisted overdenture (PIOD) opposed by lower implant retained overdenture. The spirometric parameters such as Vital capacity (VC), Forced expiratory volume in 1 second $\left(\mathrm{FEV}_{1}\right)$, the Ratio $\mathrm{FEV}_{1} / \mathrm{FVC}$ (Forced vital capacity), Peak expiratory flow (PEF), and Maximum expiratory

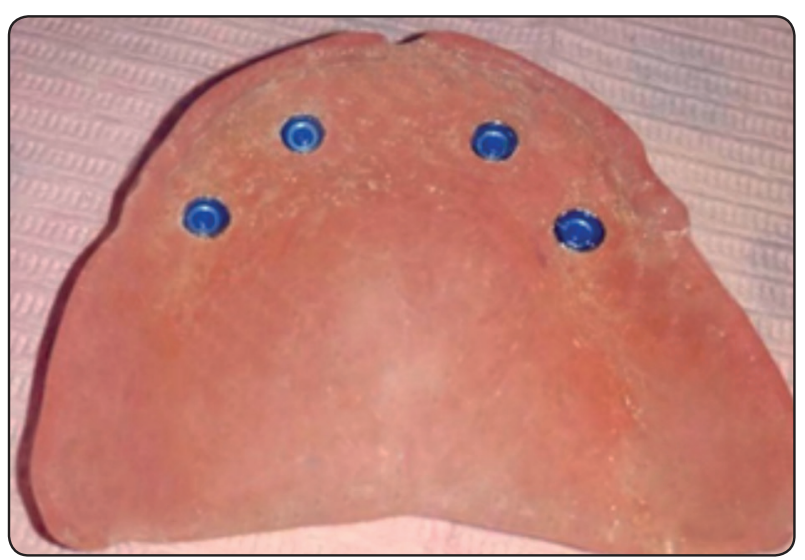

Fig. (2) Maxillary implant assisted overdenture with complete palatal coverage. 


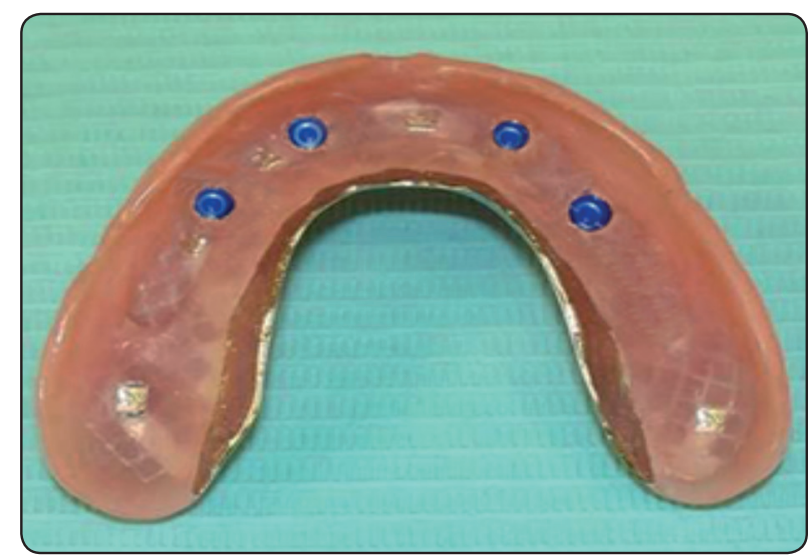

Fig. (3) Palateless maxillary implant assisted overdenture

flow between $25-75 \%\left(\mathrm{MEF}_{25-75}\right)$ were measured for each oral conditions. To decrease the effect of treatment order on spirometric measurements, 7 subjects randomly received maxillary implant assisted overdenture with palatal coverage (MIOD) first and the other 7 subjects received the palateless maxillary implant assisted overdenture (PIOD). The patient's names were included in opaque sealed envelopes of the same size and shape. The envelopes were successively numbered from 1 to 14 using a pin. Distribution of participants to (MIOD) and (PIOD) groups was carried out using random numbers (from 1 to 14 ) created in excel sheet.

\section{Statistical analysis}

Data were collected and analyzed using the SPSS 20.0 Software Program (SPSS, Inc., Chicago, IL, USA). For multiple comparisons into groups Friedman test was used. To carry out dual comparisons between oral conditions, Wilcoxon signed ranked test was used for irregularly distributed variables, and paired samples $t$ test was used for regularly distributed variables. The confidence level was set at $\mathrm{p}<0.05$.

\section{RESULT}

The mean values of the spirometric parameters $\mathrm{VC}, \mathrm{FEV}_{1}$, ratio $\mathrm{FEV}_{1} / \mathrm{FVC}, \mathrm{PEF}$, and $\mathrm{MEF}_{25-75}$ for the different oral conditions WOP, MIOD, and

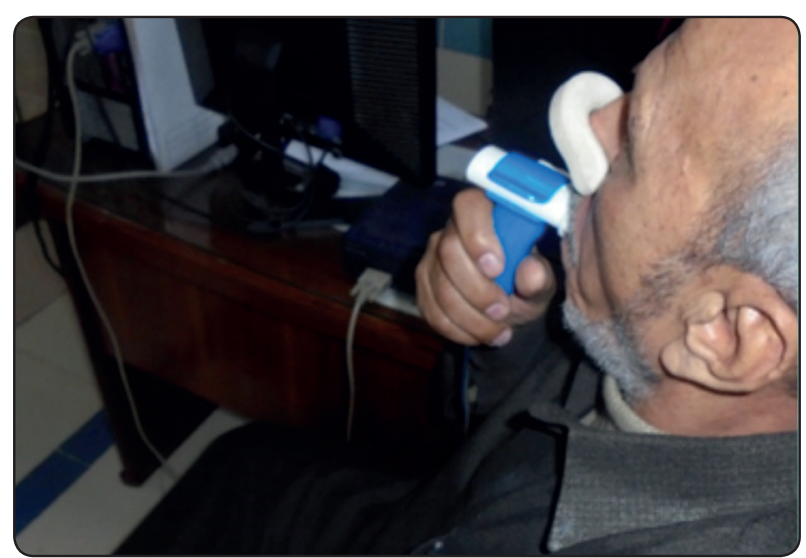

Fig. (4) Patient doing spirometric test.

PIOD were showed in table (1). The highest values were showed in the palateless maxillary implant overdenture and the lowest values were showed in without prosthesis oral state.

TABLE (1): Mean values of spirometric parameters of all subjects for without prosthesis (WOP), with maxillary implant overdenture with palatal coverage (MIOD), and with palateless maxillary implant overdenture (PIOD).

\begin{tabular}{|c|c|c|c|}
\hline & WOP & MIOD & PIOD \\
\cline { 2 - 4 } & Mean \pm SD & Mean \pm SD & Mean \pm SD \\
\hline VC & $3.9 \pm 0.24$ & $4.1 \pm 0.31$ & $4.6 \pm 0.46$ \\
\hline FEV1 & $3.41 \pm 0.36$ & $3.44 \pm 0.41$ & $3.5 \pm 0.32$ \\
\hline FEV1/FVC & $84.1 \pm 3.9$ & $88.2 \pm 5.7$ & $91.3 \pm 4.7$ \\
\hline PEF & $6.5 \pm 0.42$ & $6.6 \pm 0.37$ & $6.7 \pm 0.54$ \\
\hline MEF75 & $5.9 \pm 0.32$ & $6.5 \pm 31$ & $7.2 \pm 0.51$ \\
\hline MEF50 & $5.5 \pm 0.37$ & $5.8 \pm 0.52$ & $6.48 \pm 0.34$ \\
\hline MEF25 & $1.5 \pm 0.17$ & $2.1 \pm 0.37$ & $2.6 \pm 0.36$ \\
\hline
\end{tabular}

The comparisons of the values for spirometric parameters between different oral conditions (WOD, MIOD, and PIOD) were showed in table (2). For values of $\mathrm{VC}, \mathrm{MEF}_{25-75}$, and $\mathrm{FEV}_{1} / \mathrm{FVC}$, There were statistically significant increase at palateless maxillary implant overdenture oral condition 
when compared to both without prosthesis oral state $(\mathrm{p}<0.05)$ and with maxillary implant assisted overdenture with palatal coverage $(\mathrm{p}<0.05)$. Also, the maxillary implant assisted overdenture with palatal coverage showed statistically significantly increase when compared to without prosthesis oral state $(\mathrm{p}<0.05)$.

There were no significant differences between the three different oral conditions for values of $\mathrm{FEV}_{1}$ and PEF $(\mathrm{p}>0.05)$.

TABLE (2) Comparison of spirometric parameters values between WOP, CIOD, and PIOD oral conditions.

\begin{tabular}{|c|c|}
\hline Comparison of spirometric values & $P$ value \\
\hline VC-WOP\&VC-MIOD & $0.02 *$ \\
\hline VC-WOP\&VC-PIOD & $0.005^{*}$ \\
\hline VC-MIOD\&VC-PIOD & $0.008 *$ \\
\hline $\mathrm{FEV}_{1}-\mathrm{WOP} \& \mathrm{FEV}_{1}-\mathrm{MIOD}$ & 0.09 \\
\hline 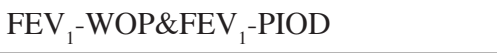 & 0.09 \\
\hline 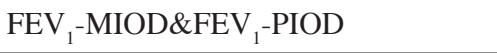 & 0.08 \\
\hline $\mathrm{FEV}_{1} / \mathrm{FVC}-\mathrm{WOP} \& \mathrm{FEV}_{1} / \mathrm{FVC}-\mathrm{MIOD}$ & $0.006^{*}$ \\
\hline $\mathrm{FEV}_{1} / \mathrm{FVC}-\mathrm{WOP} \& \mathrm{FEV}_{1} / \mathrm{FVC}-\mathrm{PIOD}$ & $0.004 *$ \\
\hline $\mathrm{FEV}_{1} / \mathrm{FVC}-\mathrm{MIOD} \& \mathrm{FEV}_{1} / \mathrm{FVC}-\mathrm{PIOD}$ & $0.03 *$ \\
\hline PEF-WOP\&PEF-MIOD & 0.12 \\
\hline PEF-WOP\&PEF-PIOD & 0.29 \\
\hline PEF-MIOD\&PEF-PIOD & 0.28 \\
\hline $\mathrm{MEF}_{25}-\mathrm{WOP} \& \mathrm{MEF}_{25}-\mathrm{MIOD}$ & $0.007 *$ \\
\hline 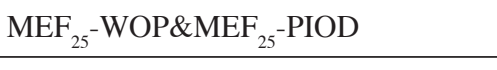 & $0.003 *$ \\
\hline $\mathrm{MEF}_{25}-\mathrm{MIOD} \& \mathrm{MEF}_{25}-\mathrm{PIOD}$ & $0.004 *$ \\
\hline 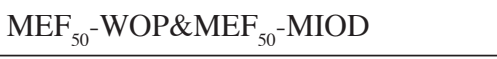 & $0.007 *$ \\
\hline 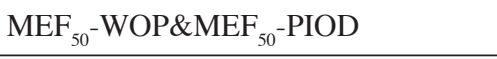 & $0.003 *$ \\
\hline $\mathrm{MEF}_{50}-\mathrm{MIOD} \& \mathrm{MEF}_{50}-\mathrm{PIOD}$ & $0.004 *$ \\
\hline 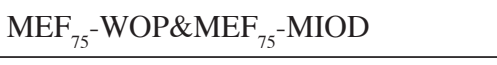 & $0.005^{*}$ \\
\hline $\mathrm{MEF}_{75}-\mathrm{WOP} \& \mathrm{MEF}_{75}-\mathrm{PIOD}$ & $0.003 *$ \\
\hline $\mathrm{MEF}_{75}-\mathrm{MIOD} \& \mathrm{MEF}_{75}-\mathrm{PIOD}$ & $0.005^{*}$ \\
\hline
\end{tabular}

*Statistically significant.

\section{DISCUSSION}

Completely edentulous state leads to prominent anatomical changes, such as reduction in vertical dimension of occlusion, mandible rotation, and reduced height of the lower third of the face that may affect the size and function of upper airway ${ }^{(31)}$. Construction of denture for completely edentulous patient is an essential part of prosthodontics treatment modality. The denture not only provide sufficient support to orofacial structures by retrieving the changed vertical dimension but also improve esthetics and phonetics and also restores the masticatory function ${ }^{(32)}$.

The results of this study showed that the use of maxillary implant overdenture (with or without palatal coverage) while performing spirometric test produced a significant improvement in values of $\mathrm{VC}, \mathrm{FEV}_{1} / \mathrm{FVC}$, and $\mathrm{MEF}_{25-75}$. This may be due to edentulous state cause a reduction in size and tonicity of pharyngeal muscles that favors pharyngeal collapse ${ }^{(19)}$ and wearing the prosthesis with acceptable vertical dimension of occlusion has an effect on extra thoracic airways involving the retropharyngeal space. This finding are in agreement with Singhal, et al. study. It was found that peak inspiratory flow rates values were increased significantly with dentures group when compared to without dentures group. However, there were no significant differences in Forced Vital Capacity (FVC), and forced expiratory volume in one second $\left(\mathrm{FEV}_{1}\right)$ with dentures groups when compared to without dentures groups ${ }^{(33)}$. Similarly, Bucca et al. compared the values of forced vital capacity (FVC), forced expiratory volume in one second $\left(\mathrm{FEV}_{1}\right)$, peak expiratory flow rate (PEFR), forced expiratory flow $\left(\mathrm{FEF}_{50 \%}\right)$, forced inspiratory volume $\left(\mathrm{FIV}_{1}\right)$, and forced inspiratory flow $\left(\mathrm{FIF}_{50 \%}\right)$ measured with and without dentures in completely edentulous subjects. They found that the edentulous subjects had significantly lower airflow rates in without dentures state. Also, the retropharyngeal space was significantly reduced in without dentures groups ${ }^{(19)}$. 
Carossa et al. observed the effect of removal of dentures and modifications of prosthesis on pharyngeal collapse and found statistically significant decrease in pharyngeal airway space. They concluded that dentures wearing induces alteration in the position of the tongue, and the pharyngeal air way space ${ }^{(34)}$.

Regarding to the effect of palatal coverage in maxillary implant assisted overdentures, the result of this study showed that using palateless maxillary implant overdenture during spirometric evaluation produce significant improvement on spirometric parameters than maxillary implant assisted overdenture with palatal coverage. This may be due to the thickness of the palatal part of the maxillary implant overdenture with palatal coverage may shift the tongue posteriorly, leading to collapse of the pharyngeal airway space ${ }^{(35)}$. Removal of the palatal part reduced the palatal bulk which in turn might have positive effect on tongue position, the associated anterior movement of the tongue's base and epiglottis may result in increased horizontal expansion of the oropharynx ${ }^{(1,36)}$. This in agreement with Piskin et al. study, they found that the oropharyngeal airflow rate being unfavorably affected by the large coverage of the palate ${ }^{(26)}$.

In a within subject study, comparison was done between maxillary implant supported overdenture with and without palatal coverage. It found that the subjects with overdentures without palatal coverage expressed a more natural feeling than with overdenture with complete palatal coverage. Also, they found a significantly better esthetic and taste sensation for overdentures without palatal coverage. Nevertheless, eliminating the palatal coverage of maxillary complete overdentures did not affect negatively the stability of the overdenture ${ }^{(15)}$.

Using within subject study design presented multiple advantages. By this study design, each subject presented as its own control, which in turn reduce the error in variation due to individual differences so that the power of the study was increased $^{(15)}$. the sample size of this study was depend on clinical findings of other crossover studies in which the authors found that a reduced sample size could be used in cross over studies without affecting the power of the results ${ }^{(37)}$.

\section{CONCLUSION}

From the result of this study, it could be concluded that:

- There was an impairment of respiratory function in without prosthesis oral condition so that rehabilitation of completely edentulous patient with dental prosthesis is mandatory to improve quality of life and respiratory function.

- Covering the palate of the edentulous patient by dental prosthesis had an adverse effect on respiratory function as using the palateless maxillary implant assisted overdenture show improvement in respiratory function in comparison to maxillary implant assisted overdenture with palatal coverage.

\section{REFERENCES}

1. Furuya J, Tamada Y, Sato T, Hara A, Nomura T, Kobayashi $\mathrm{T}$ et al. Wearing complete dentures is associated with changes in the three-dimensional shape of the oropharynx in edentulous older people that affect swallowing. Gerodontology 2015; 33: 513-521.

2. Roessler DM. Complete denture success for patients and dentists. Int Dent J 2003; 53: 340-345.

3. Koike T, Ishizaki K, Ogami K, et al. Influence of anterior palatal coverage on perception and retention in complete dentures. J Prosthet Dent 2011; 105: 272-279.

4. Zarb GA, Bolender CL, Eckert SE, et al. Prosthodontic treatment of edentulous patients. Complete Dentures and Implant-Supported Prostheses 13th Ed. St.Louis: Mosby, 2013.

5. Mc Guire L, Millar K, Lindsay S. A treatment trial of an information package to help patients accept new dentures. Behav Res Ther 2007; 45: 1941-1948. 
6. Stelzle F, Ugrinovic B, Knipfer C, et al. Automatic, computer-based speech assessment on edentulous patients with and without complete dentures - preliminary results. J Oral Rehabil 2010; 37: 209-216.

7. Goiato MC, Ribeiro PDP, Garcia AR, et al. Complete denture masticatory efficiency: a Literature review. J Calif Dent Assoc 2008; 36: 683-686.

8. Gokce HS, Gokce S, Akin E, et al. Effects of complete denture wearing on the head posture and posterior airway space. J Dental Sci 2011; 6: 6-13.

9. de Albuquerque Junior RF, Lund JP, Tang L, et al. Within subject comparison of maxillary long-bar implant-retained prostheses with and without palatal coverage: patient-based outcomes. Clin Oral Implants Res 2000; 11:555-565.

10. Kiener P, Oetterli M, Mericske E, Mericske-Stern R. Effectiveness of maxillary overdentures supported by implants: maintenance and prosthetic complications. Int $\mathrm{J}$ Prosthodont 2001; 14:133-140.

11. Sadowsky SJ. Treatment considerations for maxillary implant overdentures: a systematic review. J Prosthet Dent 2007; 97:340-348.

12. Strassburger C, Kerschbaum T, Heydecke G. Influence of implant and conventional prostheses on satisfaction and quality of life: a literature review. Part 2: qualitative analysis and evaluation of the studies. Int J Prosthodont 2006; 19:339-348.

13. Colon A, Kotwal K, Mangelsdorff AD. Analysis of the posterior palatal seal and the palatal form as related to the retention of complete dentures. J Prosthet Dent 1982; 47: 23-27.

14. Orstavik JS, Floystrand F. Retention of complete maxillary dentures related to soft tissue function. Acta Odontol Scand 1984; 42:313-320.

15. Zembic A, Tahmaseb A, Wismeijer D. Within-Subject Comparison of Maxillary Implant-Supported Overdentures with and without Palatal Coverage. Clin Implant Dent Relat Res 2015; 17(3):570-579.

16. Akeel R, Assery M, al-Dalgan S. The effectiveness of palateless versus complete palatal coverage dentures (a pilot study). Eur J Prosthodont Restor Dent 2000; 8:63-66.

17. Al-Zubeidi MI, Alsabeeha NH, Thomson WM, Payne AG. Patient satisfaction with maxillary 3-implant overdentures using different attachment systems opposing mandibular 2-implant overdentures. Clin Implant Dent Relat Res 2012;14 (Suppl 1):e11-e19.
18. Pierce R. Spirometry: An essential clinical measurement. Aust Fam Physician 2005; 34: 535-539.

19. Bucca CB, Carossa S, Colagrande P, Brussino L, Chiavassa G, Pera P, Rolla G, Preti G. Effect of edentulism on spirometric tests. Am J Respir Crit Care Med. 2001 Mar;163(4):1018-20.

20. Gupta P, Thombare R, Singhal S, Pakhan AJ. Obstructive sleep apnea and edentulism-role of complete dentures/oral appliance from prosthodontic respective: a review. Indian J Sleep Med 2010; 5:116-119.

21. Choi JK, Hur YK, Lee JM, et al. Effects of mandibular advancement on upper airway dimension and collapsibility in patients with obstructive sleep apnea using dynamic upper airway imaging during sleep. Oral Surg Oral Med Oral Pathol Oral Radiol Endod 2010; 109: 712-719.

22. Muto T, Yamazaki A, Takeda S. A cephalometric evaluation of the pharyngeal airway space in patients with mandibular retrognathia and prognathia, and normal subjects. Int J Oral Maxillofac Surg 2008; 37: 228-231.

23. Martin O, Muelas L, Vinasa MJ. Nasopharyngeal cephalometric study of ideal occlusions. Am J Orthod Dentofacial Orthop 2006; 130: 436.e1-436. e9.

24. Devlin H. Complete dentures: A clinical manual for the general dental practitioner. Berlin: Springer; 2002. pp. 3359.

25. Dorner S, Zeman F, Koller M, Lang R, Handel G, Behr M. Clinical performance of complete dentures: a retrospective study. Int J Prosthodont. 2010;23:410-417.

26. Piskin B, Sipahi C, Karakoc O, Atay A, Ciftci F, Tasci C, Akin H, Arisan V, Sevketbeyoglu H, Turker T. Effects of complete dentures on respiratory performance: spirometric evaluation. Gerodontology. 2014 Mar;31(1):19-24.

27. Ahuja S, and Cagna DR. Classification and management of restorative space in edentulous implant overdenture patients. J Prosthet Dent 2011; 105: 332-337.

28. Abdelhamid AM, Hanno KI, Imam MH. A prospective cross-over study to evaluate the effect of two different occlusal concepts on the masseter muscle activity in implant-retained mandibular overdentures. Int J Implant Dent 2015; $1: 32$.

29. American Thoracic Society. Standardization of spirometry, 1994 update. Am J Respir Crit Care Med 1995; 152: $1107-1136$. 
30. Indrakumar HS, Venkatesh D, Adoni VV, Kashyap R, Jayanthi D, Prakash N. Spirometric Assessment of Impact of Complete Dentures on Respiratory Performance: An in vitro Study. J Contemp Dent Pract 2018;19(2):177-180.

31. Morelli DL, Jackson N, Gislason T, Arnardottir ES. The effect of edentulism on a hyoid, and tongue morphology in iceland sleep apnea cohort (ISAC). Am J Respir Crit Care Med 2011;183: 3676.

32. Gupta P, Thombare R, Pakhan AJ, Singhal S. Cephalometric evaluation of the effect of complete dentures on retropharyngeal space and its effect on spirometric values in altered vertical dimension. ISRN Dent 2011; 51: 69.

33. Singhal P, Singhal S, Dagar A. Impact of dentures wearing on spirometric values; data from tertiary rural center.
International Journal of Contemporary Medical Research 2018;5(4):D12-D14.

34. Carossa S, Pera P, De Lillo A, Corsalini M, Lombardo S, Bucca C. The influence of edentulism on spirometric values. Minerva Stomatol 2000 Sep;49(9):405-408.

35. Gokce HS, Gokce S, Akin E, et al. Effects of complete denture wearing on the head posture and posterior airway space. J Dental Sci 2011; 6: 6-13.

36. Cheng CF, Peng CL, Chiou HY, and Tsai CY. Dentofacial morphology and tongue function during swallowing. Am J. Orthod Dentofacial Orthop. 2002;122:491-9.

37. Henke C, Budweiser S and Jörres R.A. Lung function and associations with multiple dimensions of dental health: a prospective observational cross-sectional study. BMC Res Notes. 2016;9:274 